Original Research Paper

\title{
New Model-Based Fault Detection Approach using Black Box Observer
}

\author{
M. Abdullah Eissa, R.R. Darwish and A.M. Bassiuny
}

Department of Mechanical Engineering, Faculty of Engineering, Helwan University, Cairo, Egypt

Article history

Received: 31-01-2019

Revised: 17-02-2019

Accepted: 14-03-2019

Corresponding Author: M. Abdullah Eissa

Department of Mechanical Engineering, Faculty of

Engineering, Helwan

University, Cairo, Egypt

Email: magdy.abdallah@h-

eng.helwan.edu.eg

\begin{abstract}
Most of the emerging engineering systems lack the presence of explicit physical insights or prior knowledge that clearly depicts the model. In such cases, the conventional observer-based fault detection is difficult to be employed because of its observer gain tuning. Herein, black box behaviors arose as a promising trend that could overcome those challenges that appears due to lacking the physical insights. Thus, this work targeted designing a reliable observer based on black box concept. The proposed observer design considers observer gain tuning, regardless the mathematical representation of the plant. Extensive simulation work has been conducted in order to verify the effectiveness of the proposed black box observer design. The results performed on DC motor advocate that the proposed black box observer operates with significantly better performance than conventional counterparts' methodologies.
\end{abstract}

Keywords: Observer, Black Box Model, Fault Detection, Motor

\section{Introduction}

Fault Detection (FD) methods are having significant roles in increasing reliability, availability and maintainability for industrial equipment. Moreover, they contribute positively to enhance the safety and proactive protection for workers and equipment (Isermann, 2006; Simani et al., 2013; Poor, 2013). High profits and low costs are targeted from investments in industrial engineering applications. In fact, FD techniques reduce maintenance costs of industrial tools and could minimize the production shutting down in order to achieve these goals. Failure prediction through early FD while the plant is still operating in a controllable zone, can help in avoiding productivity loss, modifying the maintenance plans and maintaining the continuity of production (Eissa et al., 2015a). Thus, incorporating the robust control systems with FD techniques is a demand. The results of the foregoing integration could help improving productivity, lowering maintenance costs and extending machinery life (Isermann, 2006).

The observer is a mathematical structure that combines sensors and plant excitation signals with knowledge of monitored plant and sensors to produce observed signals (Frank and Ding, 1997; Luenberger, 1971). The normal imprint of the system is taken by the observer and compared with abnormal events to generate the residual signal. Residual generation is the main stage in the model-based fault detection. The residual should be equal to zero at normal operation condition and different from zero at abnormal operation (faulty cases). Although there exist many strategies to construct modelbased fault detection, observer techniques are still widely used (Simani et al., 2013; Poor, 2013; Eissa et al., 2015b; Frank and Ding, 1997; Luenberger, 1971). Different algorithms of observers were developed such as Luenberger observer, Kalman observer, unknown input observer, sliding mode observer (Ellis, 2002; Liu and Collins, 2006; Vinodh et al., 2013).

Many recent works studied observer developments and modifications (Eissa et al., 2015b; Vinodh et al., 2013; Ruderman and Iwasaki, 2014; Alkaya and Eker, 2014; Sobhani and Poshtan, 2012). A bunch of researchers considered FD techniques, where the rest tackled control aspects. Improved Luenberger structure with observer gains tuned based on an ho was used as a fault detection filter (Boizot et al., 2007). A timeindependent adaptive gain extended Kalman filter proofed theoretically and practically to DC motor (Chowdhury and Chen, 2007). A modified fault indicator based on the observer output residual for linear timeinvariant systems has been presented in ( $\mathrm{Li}$ and Yang, 2012). A dynamic observer-based robust control and FD techniques for linear systems were proposed to give 
better performance in ( $\mathrm{Li}$ and Yang, 2012). An F-18 aircraft is applied as a case study to show the effectiveness of the FD techniques and control performance in (Yi et al., 2014). A robust adaptive observer design was introduced to solve the problem of actuator FD in Braking System with disturbances and model uncertainties (Yi et al., 2014). Gadsden et al. (2013), new model-based estimators were introduced based on the interacting multiple model (IMM) strategy combined with the Smooth Variable Structure Filter (SVSF) and SVSF time-Varying smoothing Boundary Layer (SVSF-VBL). The new strategies were applied to an aerospace actuator referred to as an Electro-Hydrostatic Actuator (EHA), which provides a comprehensive system for fault detection and diagnosis. Design and real-time validation of a modified Luenberger observer for a twomass drive system using fuzzy logic were presented in (Szabat et al., 2015), the authors in (Szabat et al., 2015) argued that the modified observer is suitable for both fault detection and control purposes.

Increasing the complexity of the industrial application led to increasing the process model uncertainty. The main challenge is to design an observer that requires minimal knowledge of complex systems. Unlike previous contributions, this paper presented a new observer structure for fault detection purpose. The main contribution of this paper is handling the observerbased design problem, with gains tuned according to minimal knowledge of the system. Optimization techniques play a significant role in setting the optimal observer gains using the proper cost function. Thus, the proposed black box model observer lined towards exploiting Genetic Algorithm (GA) in order to determine the observer gains. Adopting the (GA) would provide possibilities for dealing with many complex industrial systems that are difficult to be represented in the form of a white mathematical model.

The rest of this paper is organized as follows: In section 2 , the proposed observer design is presented. The simulation results of DC motor FD compared with Kalman filter in section 3. Results analysis are illustrated in section 4 . The summary of the work is concluded in section 5 , followed the possible direction of future work.

\section{The Proposed Observer Design}

The proposed observer comprises two main stages: The first one is the predictor stage that uses the system model to form a copy of the system. And, the second one is the corrector stage, in which the notion of how error your estimation is added to the model based on determining the suitable observer gain as shown in Fig. 1 (Poor, 2013; Szabat and Serkies, 2009). The correction stage in the proposed observer based on two gains to minimize the estimation error. Figure 2 illustrated the architecture of the proposed observer scheme. It should be noted that the measured output of the system is $y$ and it is estimated by $\hat{y}$ in addition, $p$ refers to the system model. Based on Fig. 2, the general structure of the proposed observer is described as:

$\left.\left.\left.\left.\hat{y}=\left(u+\left(L_{p}(y-\hat{y})+L_{i} * \int(y-\hat{y})\right) d t\right)\right) d t\right)\right) * p\right)$

where, the $u$ is the control input signal and $L_{p}$ and $L_{i}$ are the proportional and integral observer gains respectively.

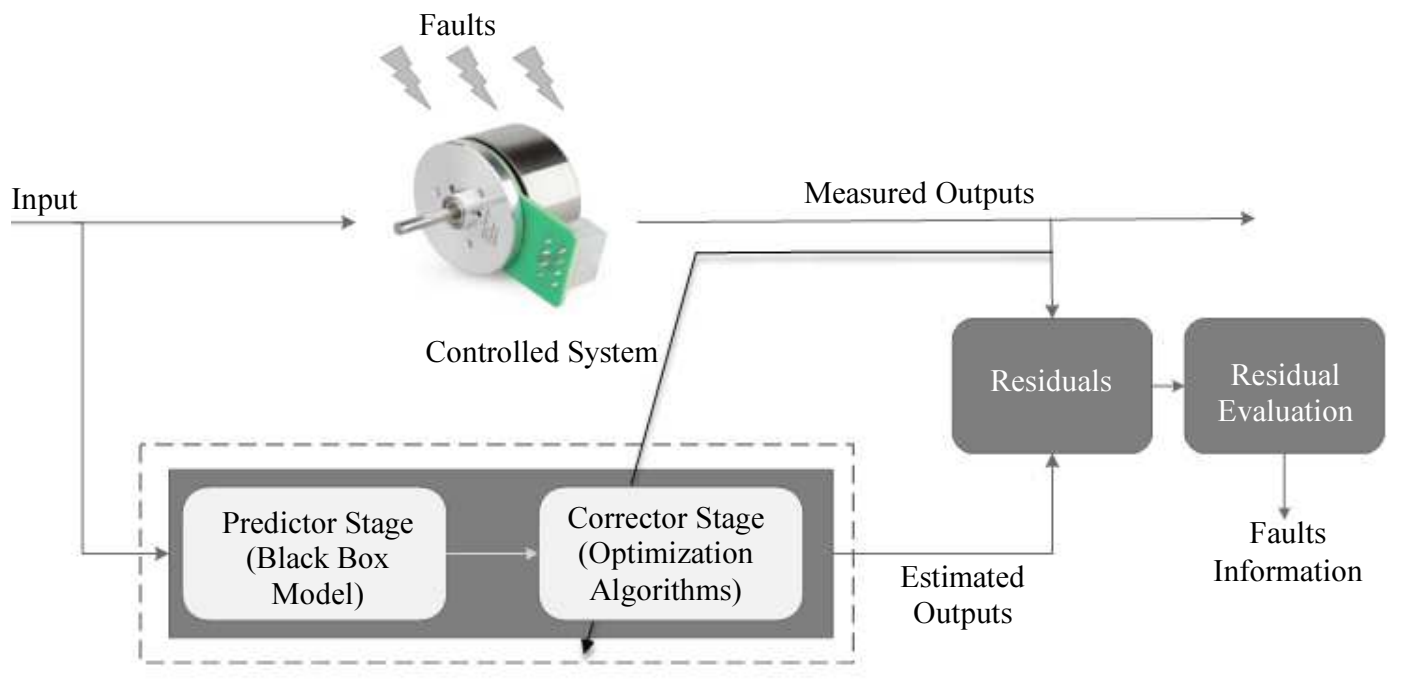

Fig. 1: Schematic diagram of proposed observer-based FD technique 


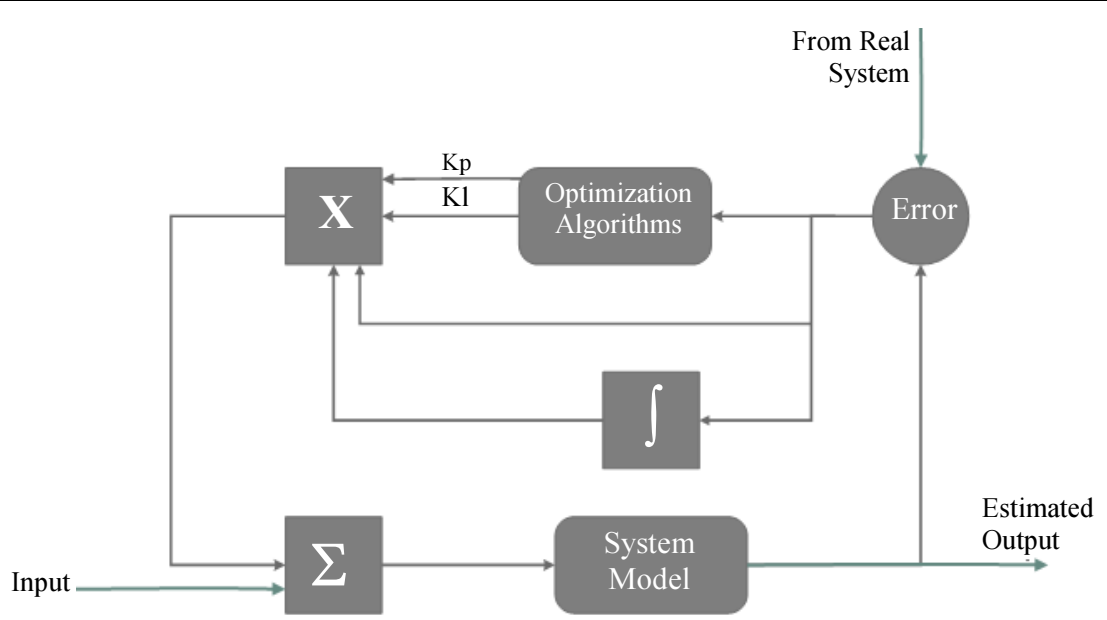

Fig. 2: Schematic diagram of the proposed observer structural

As previously mentioned, defining the observer gain is accomplished through exploiting optimization techniques. The main objective here is to determine the best observer gain that is less sensitive to model uncertainty, disturbances, meanwhile, more sensitive to the faults. The cost function that has been used is defined in Equation (2), here in the main objective is to minimize the integrated square error $e(t)$ :

$$
\text { Fitness }=\sum e^{\wedge} 2
$$

where, $e$ is the estimation error.

The design steps of the proposed Black Box observer can be summarized as follows:

Step 1: Determine the measured output of the system using the target FD sensor.

Step 2: Determine the black box model of the system that is expressed as $p$.

Step 3: Put the initial range of the optimization techniques.

Step 4: Run the optimization algorithm to find optimal observer gains according to the fitness function.

Step 5: Determine the optimal observer gain and test the gain under the normal and faulty cases.

Step 6: Repeat step 3 to 5 with another initial range until satisfactory results are reached.

Step 7: Determine the estimated value of the system output using Equation (1). Also, flow chart of proposed observer algorithm shown in Fig. 3

\section{Performance Evaluation}

\section{Simulation Study}

The Firstly, a simulation study on a DC motor sensor fault detection to report the effectiveness of the proposed observer. The DC motor here is Maxon RE25, $10 \mathrm{~W}$, precious metal brushes. The model of the DC motor is available online at (Roger Aarenstrup, 2016).

In this study, the Kalman filter that is presented in (Roger Aarenstrup, 2016) has been adopted to work as a fault detector. Also, the proposed observe has been designed to follow the steps were illustrated in section 2 .

Simulation results investigated four different cases:
a) Normal case
b) Abrupt fault case
c) Intermittent faults
d) Sensor failure

At normal case (non faulty), where there is no applied fault, the real speed and its estimated value by the proposed observer is presented in Fig. $4 \mathrm{a}$ and the residual signal depicted in Fig. 4b. Figure 5a shows the real speed and estimated speed using Kalman filter, also the residual signal is shown in Fig. 5b.

At the abrupt fault case, this fault leads to a sudden constant change in the reading values by the sensor. In order to simulate this fault, it is modelled as a step function and applied suddenly in the real output speed at the specific time. Figure 6 a displayed the results of real speed and estimated speed, however, residual signals with the proposed Black Box observer shown at Fig. $6 \mathrm{~b}$. On the other side, Fig. $7 \mathrm{a}$ and $7 \mathrm{~b}$ present the results of Kalman filter. The results illustrate the success of the observers in detecting the fault at the time of its occurrence.

In the case of the intermittent fault, a constant change in the sensor values arises in discrete intervals with different amplitudes. So, this fault could be generated as a combination of the impulses. Figure 8 and 9 presents the real speed, estimated speed and residuals signals of intermittent fault for both observers. 


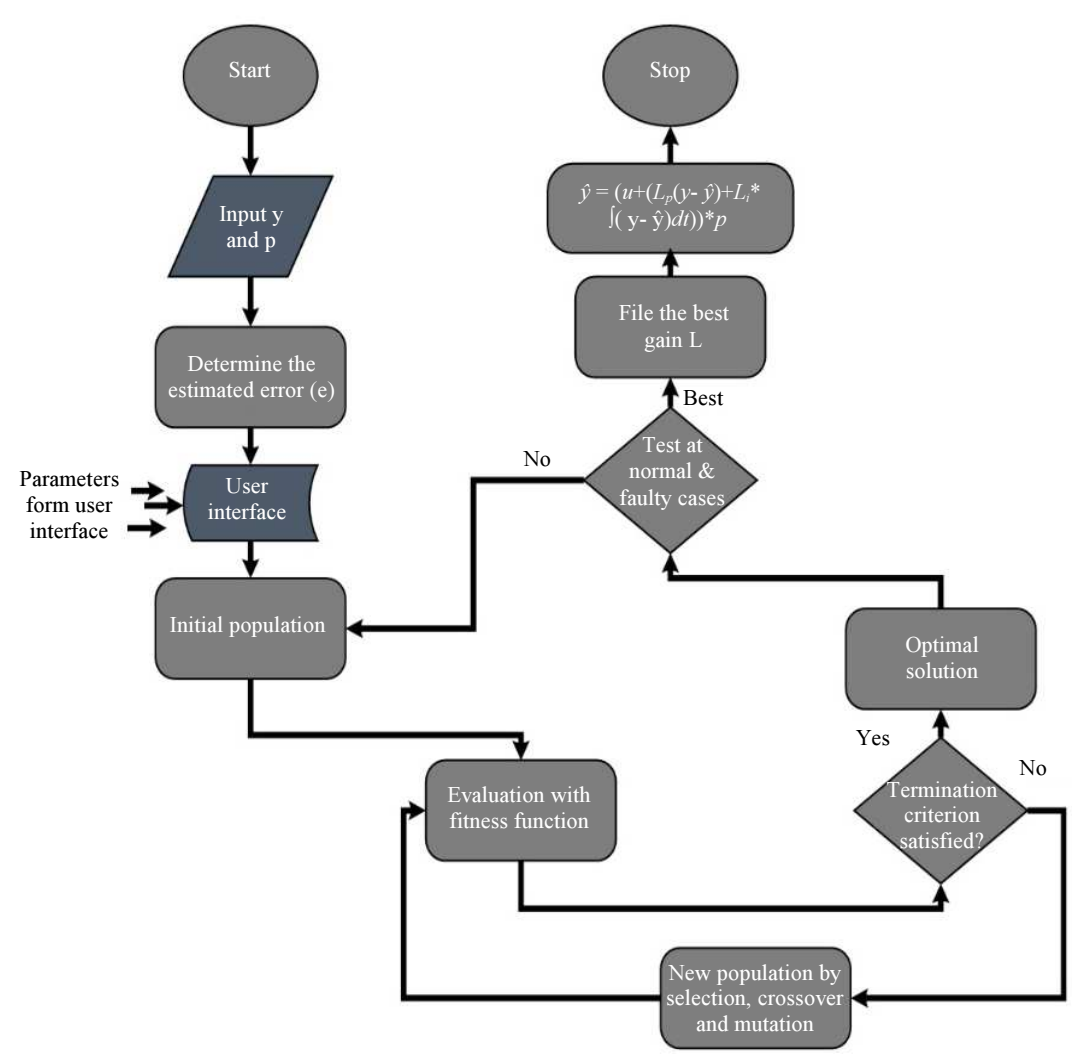

Fig. 3: Flow chart of proposed observer algorithm
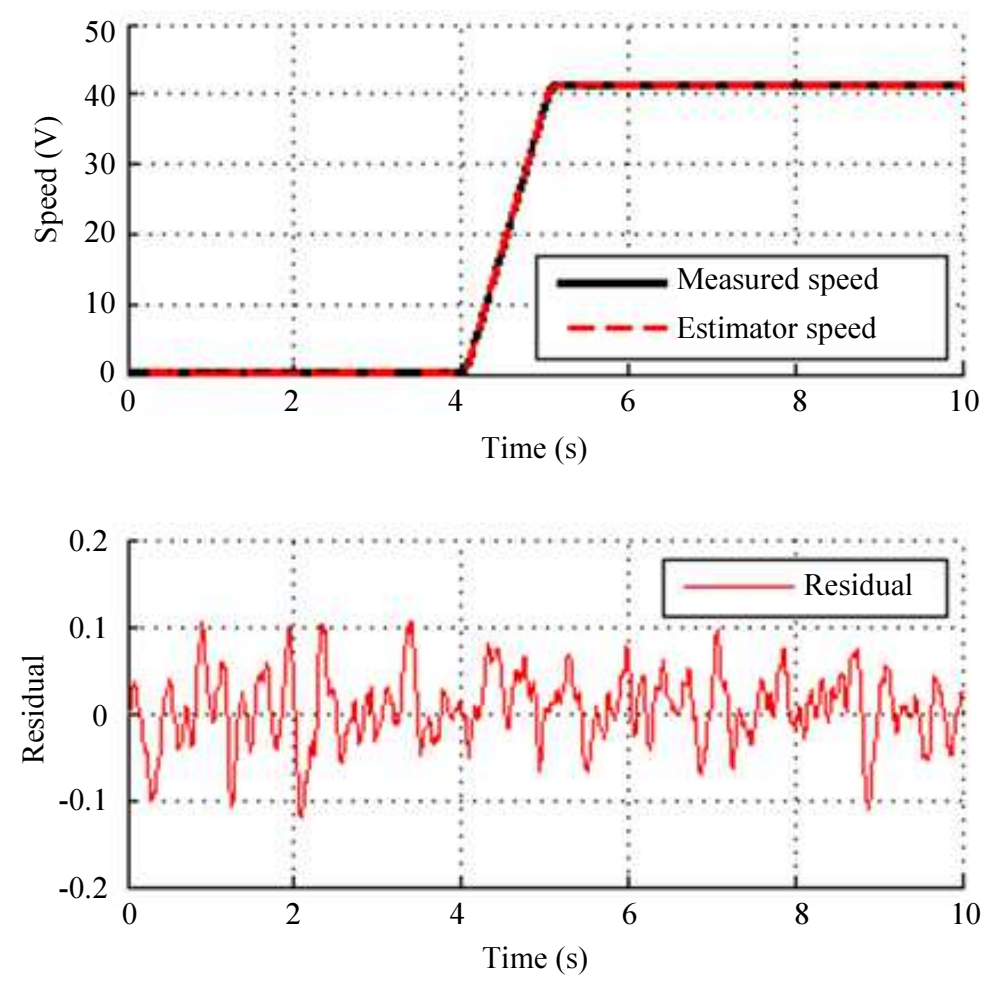

Fig. 4: Normal case: (a) real speed and estimated speed (b) Residual by the proposed Black Box observer 

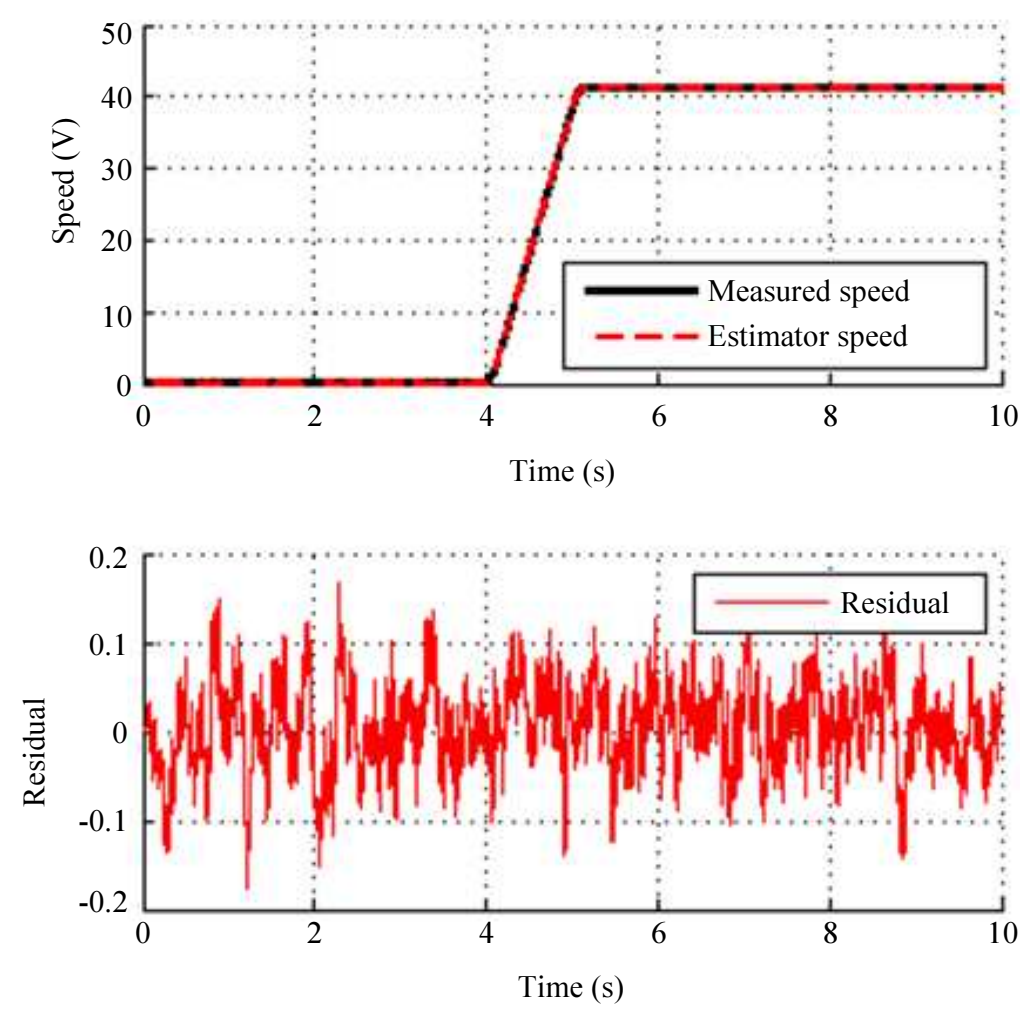

Fig. 5: Normal case: (a) real speed and estimated speed and (b) Residual by Kalman filter
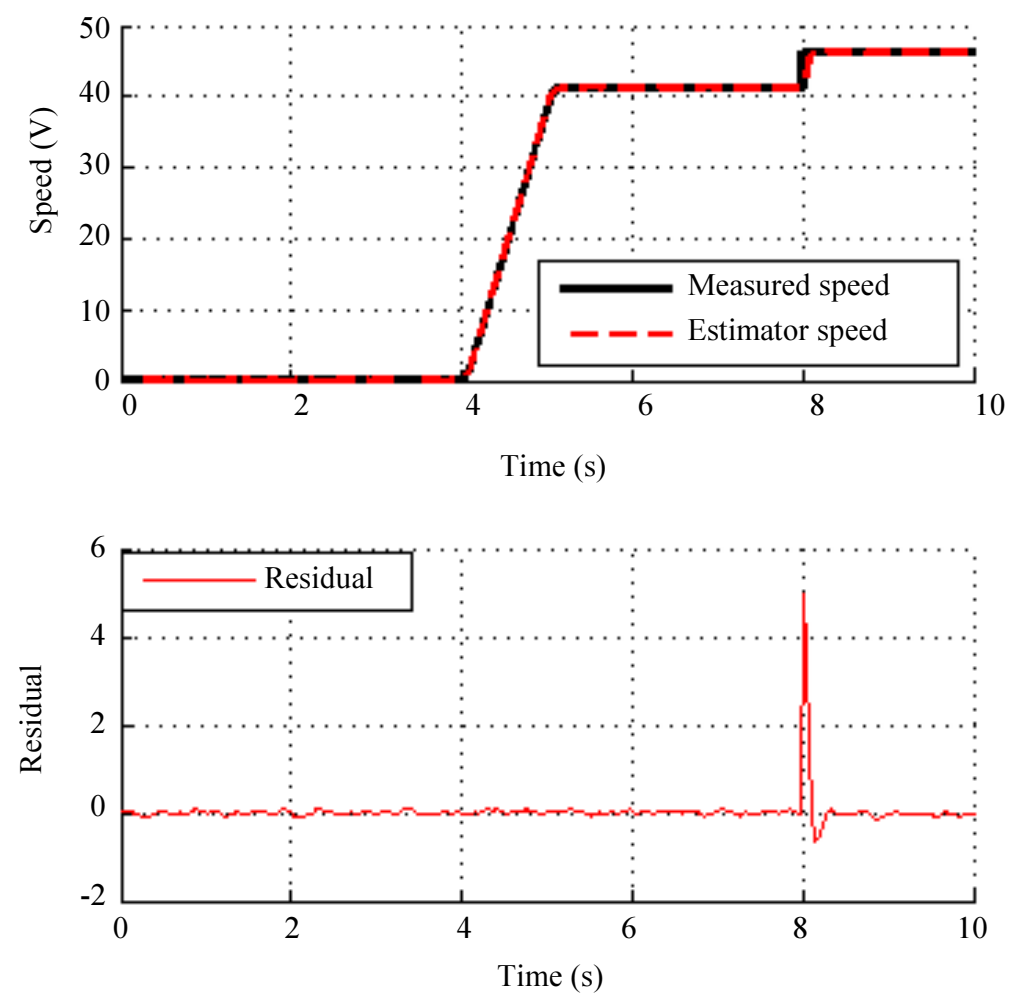

Fig. 6: Abrupt Fault case: (a) real speed and estimated speed, (b) Residual by the proposed Black Box observer 

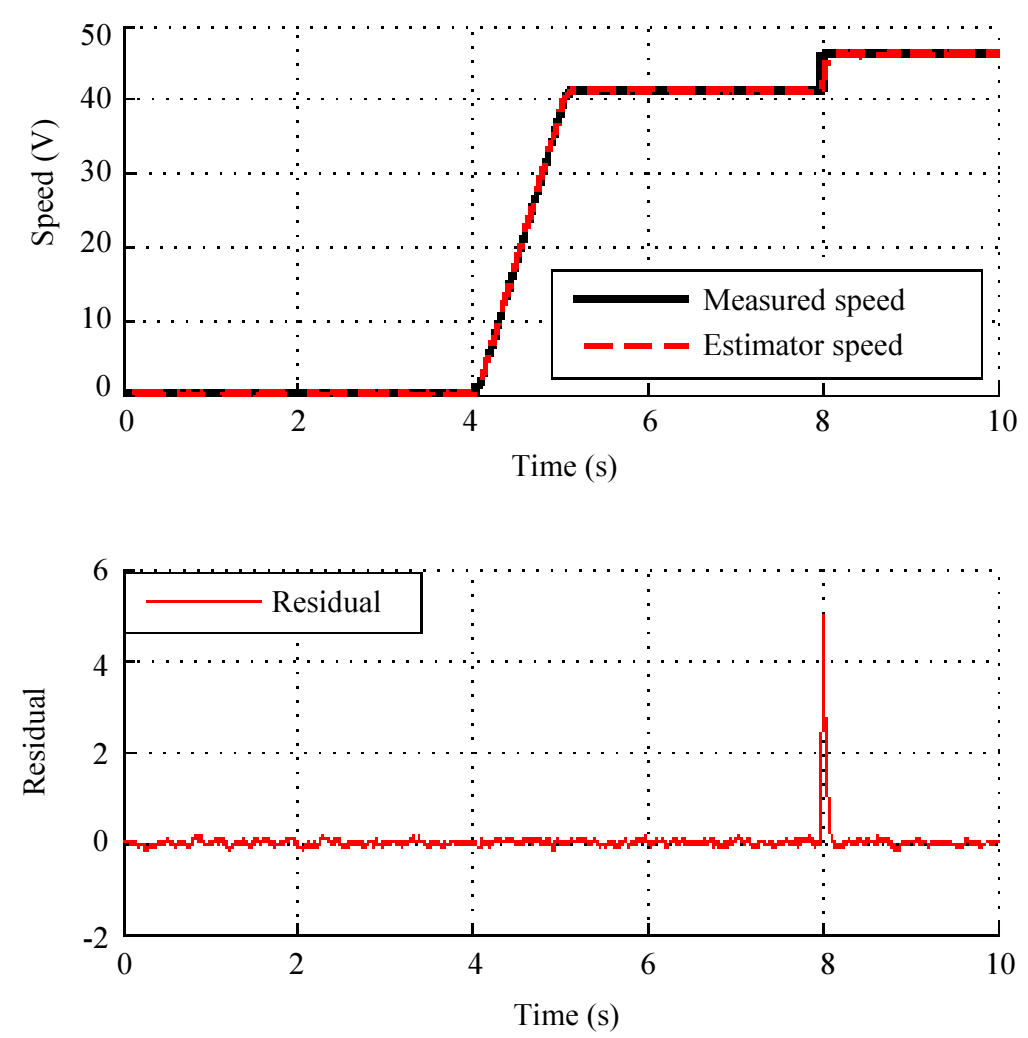

Fig. 7: Abrupt Fault case: (a) real speed and estimated speed (b) Residual by the proposed Black Box observer
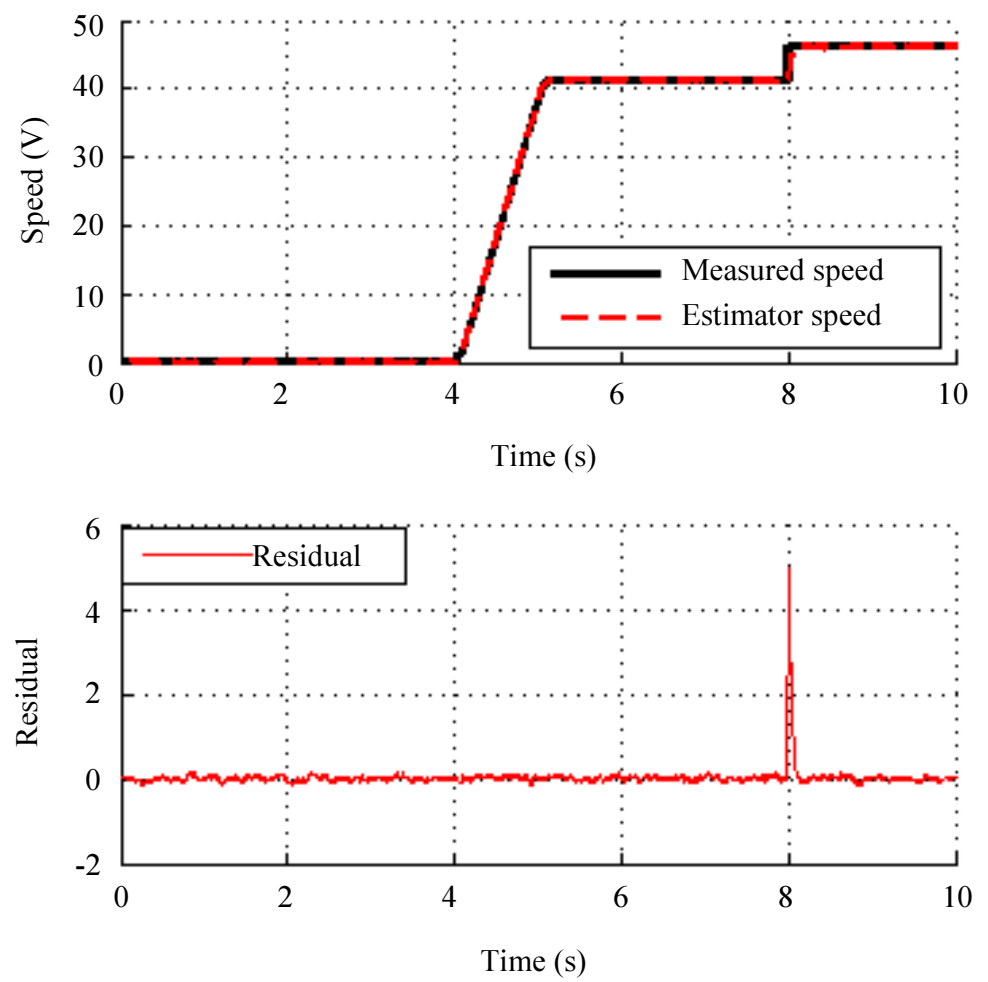

Fig. 8: Abrupt Fault case: (a) real speed and estimated speed and (b) Residual by Kalman filter 

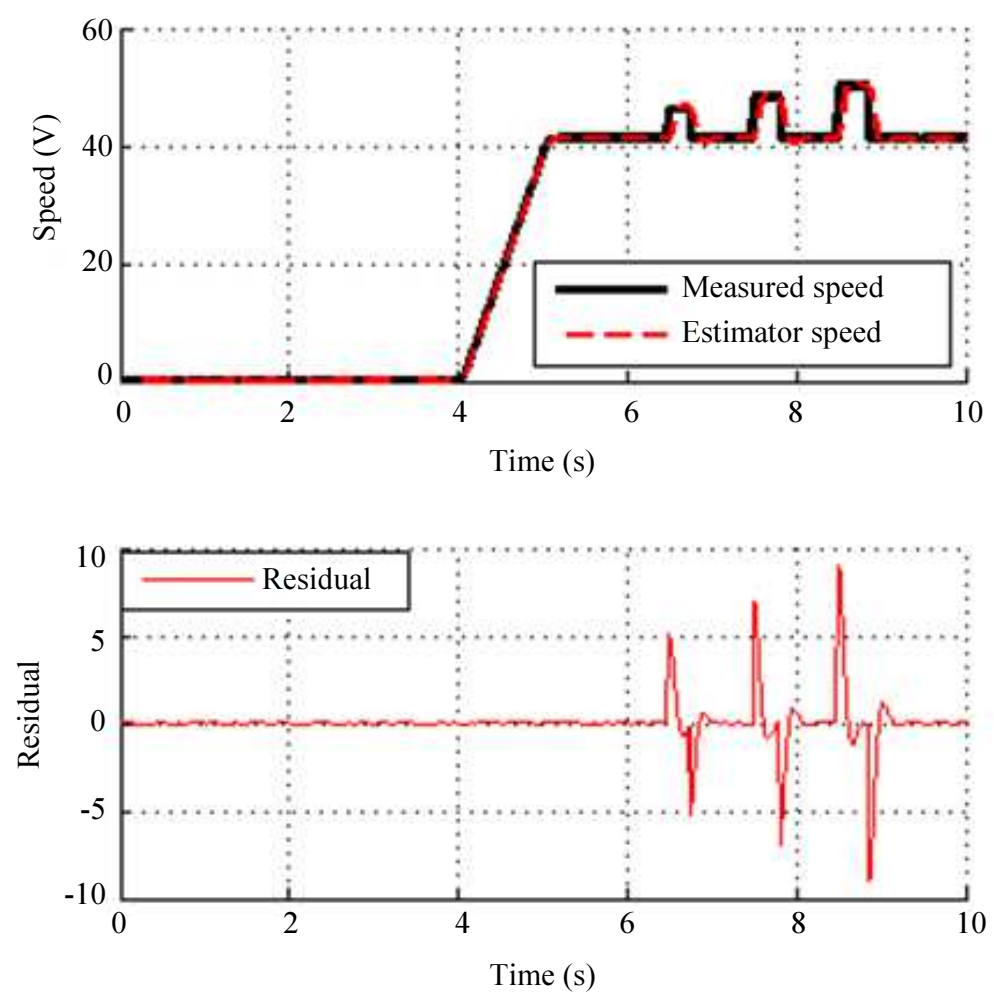

Fig. 9: Intermittent Fault case: (a) real speed and estimated speed, (b) Residual by the proposed Black Box observer, (c) real speed and estimated speed and (d) Residual by Kalman filter
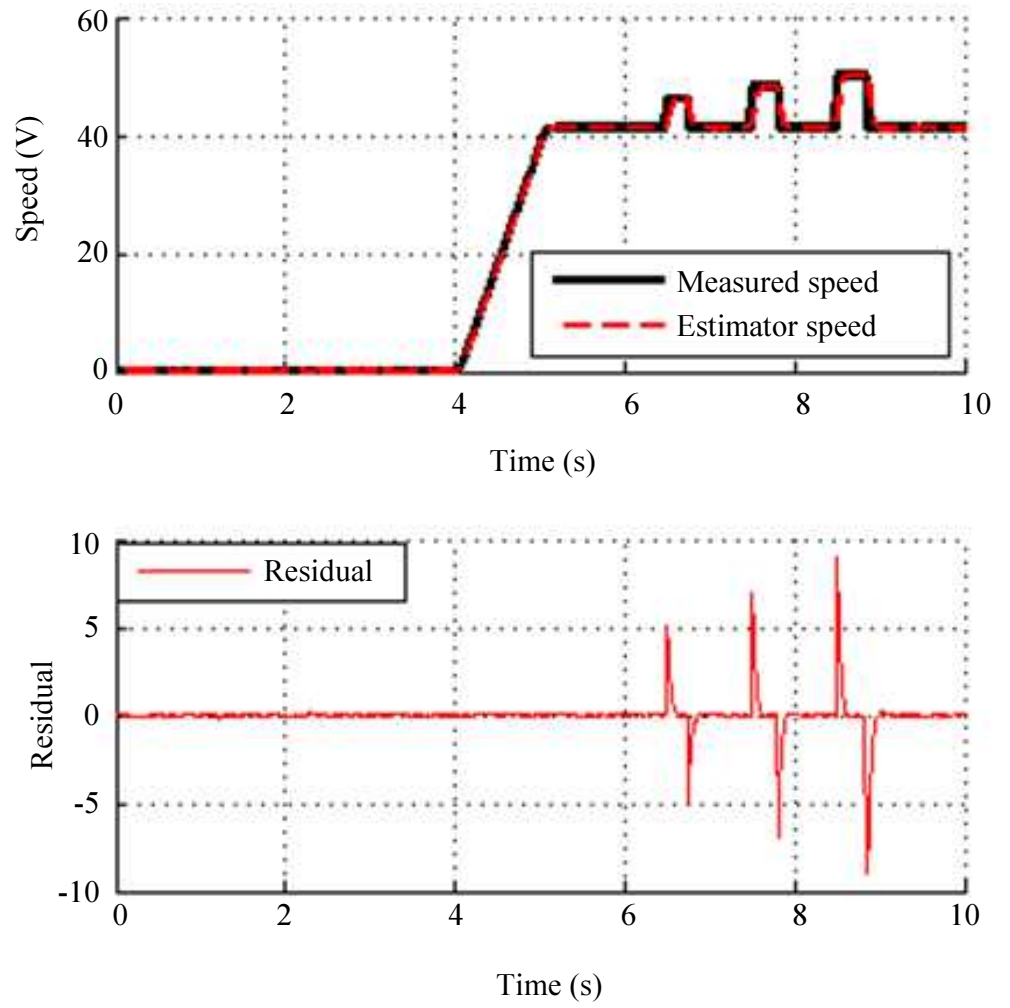

Fig. 10: Intermittent Fault case: (a) real speed and estimated speed and (b) Residual by Kalman filter 

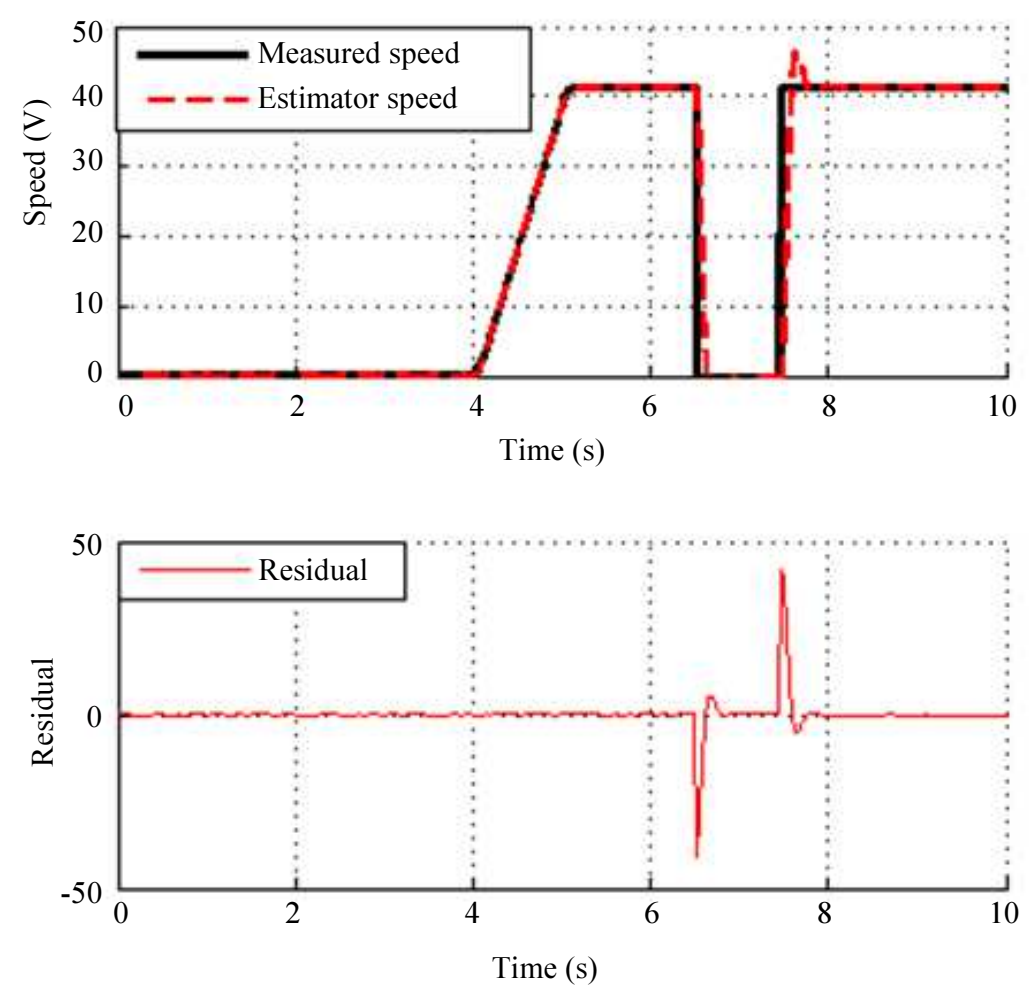

Fig. 11: Sensor failure case: (a) real speed and estimated speed (b) Residual by the proposed Black Box observer

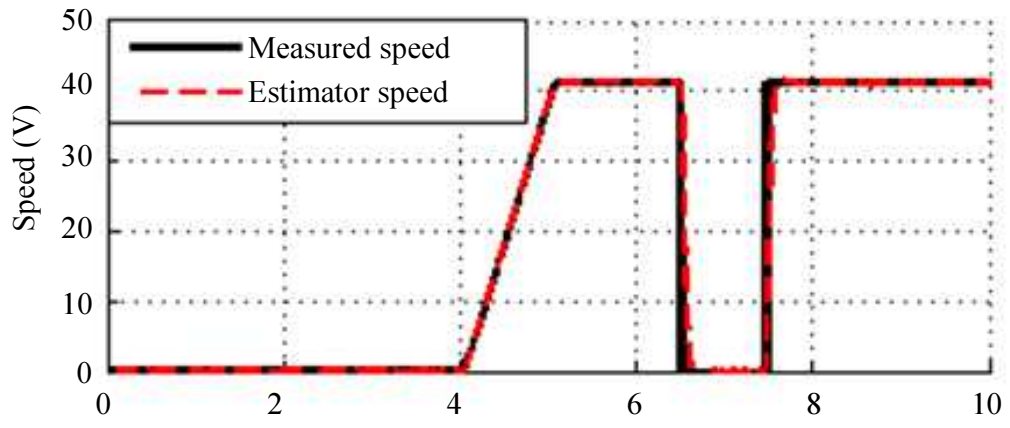

Time (s)

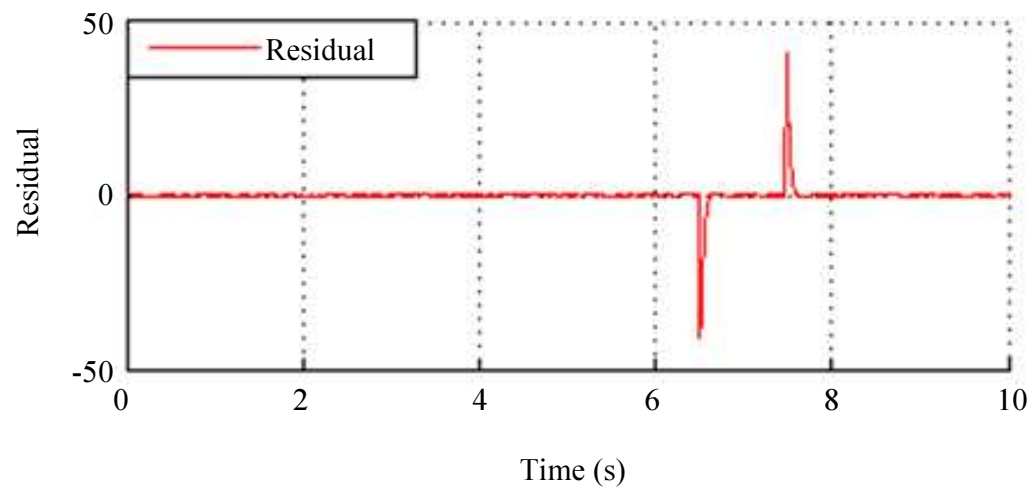

Fig. 12: Sensor failure case: (a) real speed and estimated speed, (b) Residual by the proposed Black Box observer, (c) real speed and estimated speed and (d) Residual by Kalman filter 
Table 1: Observer's estimation errors

\begin{tabular}{lll}
\hline Estimation error(e) & Proposed observer & Kalman filter \\
\hline e $(\mathrm{rpm}) / \mathrm{DC}$ motor & 0.3113 & 0.3742 \\
\hline
\end{tabular}

The sensor failure case is generated by disconnecting the speed sensor for a short time and reconnecting it again. The speed is estimated by the proposed observer and Kalman observer and then compared with the real one as depicted in Fig. 10.

The sensor failure case is generated by disconnecting the speed sensor for a short time and reconnecting it again. The speed is estimated by the proposed observer and Kalman observer and then compared with the real one as depicted in Figure 11 and 12.

\section{Results Analysis}

The These Five cases verify all results: Normal (non-faulty) case, abrupt fault case, incipient fault case, intermittent fault case and the sensor faultier fault case. At normal case, the proposed Black Box observer estimation error has been compared with the Kalman observer as shown in Table 1. The estimation errors were calculated using the following equation (Szabat et al., 2015):

$$
\Delta_{v}=\frac{\sum_{i=1}^{N}|v-v e|}{N}
$$

Where:

$N=$ The total number of samples

$v=$ The real variable

$v e=$ The estimated variable

The results show that the estimated error of the proposed observer is less than the estimated error of the traditional observers. Finally, all simulations results that have been presented in this work and also the results that were published in (Alkaya and Eker, 2014; (Tarantino et al., 2000) have advocated the proposed Black Box observer is a good estimator for fault detection purposes.

\section{Conclusion}

New observer design is presented during this work for FD purpose. Two studies were presented through this work, a simulation study on DC motor. Luenberger observer rather than the proposed observer design are camper the effectiveness of the proposed observer for FD purpose by comparing their results. As part of the future work, two tracks would be investigated. The first track tries to develop the gain tuning method to be adaptive. In the second track, the proposed observer will be applied for a complex industrial application.

\section{Author's Contributions}

M. Abdullah Eissa: Designed the observers, developed the theoretical framework the results analysis and compare the simulation results.

R.R. Darwish: Developed the theoretical framework, paper review and supervised the research.

A.M. Bassiuny: Developed the theoretical framework and supervised the research.

\section{Ethics}

This article is an original research paper. There are no ethical issues that may arise after the publication of this manuscript.

\section{References}

Alkaya, A. and I. Eker, 2014. Luenberger observer-based sensor fault detection: Online application to DC motor. Turk. J. Electrical Eng. Comput. Sci., 22: 363-370. DOI: 10.3906/elk-1203-84

Boizot, N., E. Busvelle, J.P. Gauthier and J. Sachau, 2007. Adaptive gain extended Kalman filter: Application to a series-connected DC motor. Proceedings of the Conference on Systems and Control, (CSC' 07), Marrakech, Morocco, pp: 16-18.

Chowdhury, F.N. and W. Chen, 2007. A modified approach to observer-based fault detection. Proceedings of the IEEE 22nd International Symposium on Intelligent Control, Oct. 1-3, IEEE Xplore Press, Singapore, pp: 539-543.

DOI: 10.1109/ISIC.2007.4450943

Eissa, M.A., M.S. Ahmed, R.R. Darwish and A.M. Bassiuny, 2015a. Model-based sensor fault detection to brushless DC motor using Luenberger observer. Proceedings of the 7th International Conference on Modelling, Identification and Control, Dec. 1820, IEEE Xplore Press, Sousse, Tunisia, pp: 1-6. DOI: 10.1109/ICMIC.2015.7409391

Eissa, M.A., M.S. Ahmed, R.R. Darwish and A.M. Bassiuny, 2015b. Improved fuzzy Luenberger observer-based fault detection for BLDC motor. Proceedings of the 10th International Conference on Computer Engineering and Systems, Dec. 23-24, IEEE Xplore Press, Cairo, Egypt, pp: 167-174. DOI: 10.1109/ICCES.2015.7393039

Ellis, G., 2002. Observers in control systems: A practical guide. 
Frank, P.M. and X. Ding, 1997. Survey of robust residual generation and evaluation methods in observer-based fault detection systems. J. Process Control, 7: 403-424. DOI: $10.1016 / \mathrm{S} 0959-1524(97) 00016-4$

Gadsden, S.A., Y. Song and S.R. Habibi, 2013. Novel model-based estimators for the purposes of fault detection and diagnosis. IEEE/ASME Trans. Mechatron., 18: 1237-1249.

DOI: 10.1109/TMECH.2013.2253616

Isermann, R., 2006. Fault-Diagnosis Systems: An Introduction from Fault Detection to Fault Tolerance. 1st Edn., Springer Science and Business Media, New York, ISBN-10: 3540241124, pp: 475.

Li, X.J. and G.H. Yang, 2012. Dynamic observer-based robust control and fault detection for linear systems. IET Control Theory Applic., 6: 2657-2666. DOI: 10.1049/iet-cta.2011.0057

Liu, L. and E. Collins, 2006. Robust fault detection and diagnosis for permanent magnet synchronous motors.

Luenberger, D., 1971. An introduction to observers. IEEE Trans. Automatic Control, 16: 596-602. DOI: 10.1109/TAC.1971.1099826

Poor, H.V., 2013. An introduction to signal detection and estimation. Springer Science and Business Media.

Roger Aarenstrup, 2016. Learning Kalman filter implementation in Simulink.

Ruderman, M. and M. Iwasaki, 2014. Sensorless control of motor velocity in two-mass actuator systems with load sensing using extended state observer. Proceedings of the IEEE/ASME International Conference on Advanced Intelligent Mechatronics, Jul. 8-11, IEEE Xplore Press, Besacon, France, pp: 360-365.

DOI: 10.1109/AIM.2014.6878105
Simani, S., C. Fantuzzi and R.J. Patton, 2013. Modelbased fault diagnosis in dynamic systems using identification techniques. Springer Science and Business Media.

Sobhani, M.H. and J. Poshtan, 2012. Fault detection and isolation using unknown input observers with structured residual generation. Int. J. Instrumentat. Control Syst., 2: 1-12. DOI: 10.5121/ijics.2012.2201

Szabat, K. and P.J. Serkies, 2009. Design and analysis of the Luenberger observers for three-inertia system. Prace Naukowe Instytutu Maszyn, Napędów i Pomiarów Elektrycznych Politechniki Wrocławskiej, Studia i Materiały, 29: 329-340.

Szabat, K., T. Tran-Van and M. Kamiński, 2015. A modified fuzzy luenberger observer for a two-mass drive system. IEEE Trans. Industrial Inform., 11: 531-539. DOI: 10.1109/TII.2014.2327912

Tarantino, R., F. Szigeti and E. Colina-Morles, 2000. Generalized Luenberger observer-based faultdetection filter design: An industrial application. Control Eng. Practice, 8: 665-671.

Vinodh, K.E., J. Jovitha and S. Ayyappan, 2013. Comparison of four state observer design algorithms for MIMO system. Archives Control Sci., 23: 243-256. DOI: 10.2478/acsc-2013-0015

Yi, J., Z. Huang, W. Liu, Y. Yang and X. Zhang et al., 2014. Actuator fault detection based on robust adaptive observer for CCBII Braking System. Proceedings of the 26th Chinese Control and Decision Conference, May 31-Jun. 2, IEEE Xplore Press, Changsha, China, pp: 2841-2846.

DOI: $10.1109 /$ CCDC.2014.6852657 